\title{
Needs Assessment For Continuing Professional Education Among Aesthetic Plastic Surgeons: Evidence From An Economically Developed Region in China
}

\author{
Jun Qiu \\ Southern Medical University \\ Yanhua Yi \\ Guilin Medical University \\ James Jia \\ Southern Medical University \\ Yong Miao \\ Southern Medical University \\ Zhiqi Hu ( $\nabla$ huzhiqidr163@i.smu.edu.cn ) \\ Southern Medical University
}

\section{Research Article}

Keywords: aesthetic plastic surgeon, demographic status, continuing professional education, needs assessment, China

Posted Date: March 31st, 2021

DOI: https://doi.org/10.21203/rs.3.rs-353239/v1

License: (c) (1) This work is licensed under a Creative Commons Attribution 4.0 International License. Read Full License 


\section{Abstract}

Background: This study aims to survey the demographic status of aesthetic plastic surgeons in an economically developed region and to investigate their continuing professional education needs in contents, training methods, and barriers in private and public hospitals.

Methods: A cross-sectional survey with a self-administered questionnaire was conducted from January to December, 2020 in Guangdong, China. An in-depth key informant interviews were conducted to gain insights on the current demographic status. Demographic data and training needs assessment were collected and compared with the chi-square test, Fisher's test, Mann-Whitney U-test using R software.

Results: The disparity of surgeons' demographic data between private and public hospitals was small. Over $60 \%$ of practicing aesthetic plastic surgeons transferred from other specialties, and one third of them had less than three years of working experience. Half surgeons attended training less than three times with an affordable expense of 1000-5000RMB. Almost $80 \%$ of them had strong willingness to attend a continuing professional education program. They prefer to attending further study in a tertiary hospital, short topic-focused training course with operation demonstrations. Their favorable training contents were rhinoplasty, eye surgery, and new technologies. Questionnaire survey revealed the likelihood that the surgeons had a graduate degree in public hospitals outweighed those in private hospitals $(\mathrm{P}<0.05)$. In-depth interview showed that the public hospitals focused more on repair and reconstructive surgery, academic research, whereas, private hospitals focused on market needs and were more profit-driven, where the organizational needs had influence on their different training needs for aesthetic plastic surgeons.

Conclusion: It would be favorable to take the demographic status of aesthetic plastic surgeons and organizational needs into consideration in designing a continuing professional education program in plastic surgery.

\section{Background}

Rapid economic development and "selfie culture" have driven Chinese plastic surgery market to grow very fast in recent years[1, 2]. It is expected that the total amount of spending in plastic procedures has increased up to approximately 122 billion US dollars by 2019, which ranks third in the world following United States and Brazil[3]. As a result, the past decade has witnessed drastic development of private aesthetic plastic hospitals owing to highly social demand for all kinds of cosmetic plastic surgeries [4]. Meanwhile, surgical doctors transfer their original practicing specialty into aesthetic plastic surgery after obtaining a training certificate from a tertiary public hospital recognized by the provincial health commission. The public hospitals serve as a training base for medical students who pursue a master degree or $\mathrm{PhD}$ degree in plastic surgery and also play pivot roles in continuing professional education for these doctors who change from other surgical specialties[5]. Private hospitals tend to develop even more faster than public hospitals due to more flexibility in management and favorable government policies. 
The total number of aesthetic plastic procedures in private hospitals has exceeded that of public hospitals [6]. Our first hypothesis is that owing to the rapid development of the plastic surgery industry, the influx of a large number of plastic surgeons will result in a very strong demand for continuing professional education in plastic surgery.

It has been documented that continuing professional education programs are significant to improve their serving quality for health professionals[7-9]. There have been various training programs available for the aesthetic plastic surgeons in recent years, which include conference sessions, further clinical education in tertiary hospitals, operation demonstrations, and online training courses. But almost all those programs are organized and dictated by hospitals or organizations, the needs of learners have rarely been assessed[10]. As Goldstein training mode suggests that training candidates, training contents, organizational requirements be the three important factors while in designing a good health training program[11]. Our second hypothesis is the difference between private and public hospital in medical service would lead to different training needs.

To date, there is a paucity of data investigating the current demographic status of aesthetic plastic surgeons both in public hospitals and private hospitals in China and their respective needs in continuing professional education. To test the above two hypotheses, this study aims to survey the demographic status of aesthetic plastic surgeons from both in public and private hospitals, and to investigate their continuing professional education needs in contents, methods, and barriers within.

\section{Study Site And Methods}

\subsection{Study site}

The study site was conducted from January to December, 2020 in Guangdong, China. As a coastal province in South China, Guangdong's GDP in 2019 surpassed 1.5 trillion US dollars, which ranked first in China [12]. In this developed economic region, it is estimated that there are more than ten public hospitals with aesthetic plastic departments and two hundred private plastic hospitals with almost eight hundred aesthetic plastic surgeons in total in 2019.

\subsection{Study design}

A mixed study combining a self-administered questionnaire survey and in-depth key informant interviews were used.

\subsection{Data collection method and instruments}

Based on literature reviews and experts' consultation, we adapted a questionnaire which was reviewed by a statistician, two epidemiologists, four dermatologists, and two plastic and aesthetic surgeons to ensure its validity. A small pilot study was conducted to verify suitability of the questions before survey.

\subsection{In-depth interview with key informants}


In-depth interviews were conducted with multiple key informants. The interview topics included comments on the current status of aesthetic plastic surgeons, current continuing professional education programs, potential problems, and solutions for the improvement. All interviews were taped and transcribed verbatim for thematic analysis.

\subsection{Statistical analysis}

All data analyses were performed using R version 3.5.2 (http://www.R-project.org/) and EpiDisplay package. Categorical data were given as counts and percentages, to compare the difference in demographic information and training needs assessment, the chi-square test, Fisher's test, were used as appropriate for categorical variables. Mann-Whitney U-test was use to compare the knowledge gap for major aesthetic surgical procedures between surgeons in private and public hospitals. Statistical significance was set at $5 \%$.

\section{Results}

\subsection{Demographic information and needs assessment on aesthetic plastic surgeons}

Demographic data of 290 aesthetic plastic surgeons completed the questionnaire survey, the responding rate was $81.5 \%$ ((290 out of 356$))$. 240 surgeons were practicing aesthetic plastic surgery after excluding those cosmetic dermatologists, and cosmetic doctors in traditional Chinese medicine.

Shown in Table 1, the distribution of gender, age groups, and years of practice, professional technical titles, and original working department was nearly the same among the 144 surgeons from public hospitals and 96 from private hospital. In general, over sixty percent of the surgeons were under 40 years of age, one third of the surgeons had less than three years of working experience with junior professional technical titles. Almost two thirds of surgeons' original working departments were not aesthetic plastic surgery. The distribution of educational degree among doctors between hospitals was statistically different. There were more doctors with a graduate degree in public hospitals. 
Table 1

Demographic data of aesthetic plastic surgeons

\section{from public and private hospitals}

\begin{tabular}{|c|c|c|c|}
\hline & Public hospital $(\mathrm{N}=144)$ & Private hospital $(\mathrm{N}=96)$ & $P$ value \\
\hline Gender & & & 0.25 \\
\hline Male & $90(62.5)$ & $52(54.2)$ & \\
\hline Female & $54(37.5)$ & $44(45.8)$ & \\
\hline Age group (years) & & & 0.69 \\
\hline$<30$ & $30(20.8)$ & $21(21.9)$ & \\
\hline $30-40$ & $70(48.6)$ & $41(42.7)$ & \\
\hline $40-50$ & $32(22.2)$ & $22(22.9)$ & \\
\hline$>50$ & $12(8.3)$ & $12(12.5)$ & \\
\hline Educational degree & & & $<0.01$ \\
\hline Associate degree or below & $6(4.2)$ & $10(10.4)$ & \\
\hline Bachelor & $72(50)$ & $61(63.5)$ & \\
\hline Graduate & $66(45.8)$ & $25(26)$ & \\
\hline Years of practice & & & 0.96 \\
\hline 1-3 year & $48(33.3)$ & $31(32.3)$ & \\
\hline $3-5$ year & $19(13.2)$ & $15(15.6)$ & \\
\hline 5-10 year & $35(24.3)$ & $23(24)$ & \\
\hline$>10$ year & $42(29.2)$ & $27(28.1)$ & \\
\hline Professional technical title & & & 0.17 \\
\hline Senior & $45(31.2)$ & $20(20.8)$ & \\
\hline Junior & $59(41)$ & $42(43.8)$ & \\
\hline Primary & $40(27.8)$ & $34(35.4)$ & \\
\hline Original working department & & & 0.62 \\
\hline Other specialty & $56(38.9)$ & $32(33.3)$ & \\
\hline Aesthetic plastic surgery & $54(37.5)$ & $37(38.5)$ & \\
\hline Other surgery & $34(23.6)$ & $27(28.1)$ & \\
\hline
\end{tabular}


Table 2 summarized the current training status and study objectives for surgeons. Overall, there were some similarities between surgeons of public and private hospitals, half of the surgeons attended training less than three times with an affordable expense of 1000-5000RMB, surgeons in private hospitals were more likely to spend more than 10,000 RMB in training. The majority of them (almost $80 \%$ ) had strong willingness to attend training to improve their practical skills, gain clinical experience, and learn latest technologies. 
Table 2

Current training status and training objectives

Public hospital $(\mathrm{N}=$

144)

Numbers of training in a year

$1-3$

3-5

$>5$

seldom

Training expense in a year (RMB)

$<1000$

$1000-5000$

$5000-10000$

$10000-20000$

$>20000$

Willingness on training

very strong

strong

fairly

no

\section{Study objectives}

theory

practical skills

clinical experience

communication skills

aesthetic judgment

team work

scientific writing

latest technology

Values are presented as number

(\%).

$1(0.7)$

19 (13.2)

35 (24.3)

$112(77.8)$

89 (61.8)

$34(23.6)$

24 (16.7)

19 (13.2)

$22(15.3)$

$48(33.3)$
Private hospital $(\mathrm{N}=$

96)

$P$ value 0.60

$49(51)$

$26(27.1)$

$17(17.7)$

$4(4.2)$

0.05

10 (10.4)

49 (51)

16 (16.7)

13 (13.5)

8 (8.3)

0.88

57 (59.4)

16 (16.7)

22 (22.9)

1 (1.0)

$20(20.8)$

0.06

74 (77.1)

1.00

49 (51)

0.13

17 (17.7)

0.35

22 (22.9)

0.30

15 (15.6)

0.73

12 (12.5)

0.68

38 (39.6)

0.39 
Table 3 concluded the surgeons' favorable training methods and reported obstacles. Further study in a tertiary hospital, short training course focusing in specific topic by corresponding experts, and operation demonstration were regarded as the top three favorable choices. The number one obstacle was "nobody can replace me at work", however, training expenses was the second obstacle for doctors in public hospitals and the third one for doctors in private hospital, in converse, "I cannot learn the skills I want" was second obstacle and third one for doctors in private and public hospital respectively.

Table 3

Favorable methods and obstacles for training

\begin{tabular}{|llll|}
\hline & $\begin{array}{l}\text { Public hospital }(\mathbf{N}= \\
\text { Favorable training methods }\end{array}$ & $\begin{array}{l}\text { Private hospital }(\mathbf{N}= \\
96)\end{array}$ & \begin{tabular}{l} 
value \\
\hline further study in tertiary hospital
\end{tabular} \\
\hline $\begin{array}{l}\text { attend short focus training course by } \\
\text { experts }\end{array}$ & $69(68.8)$ & $49(51)$ & 0.01 \\
\hline online computer courses & $28(19.4)$ & $43(44.8)$ & 0.81 \\
\hline online courses on smart phone & $54(37.5)$ & $18(18.8)$ & 1.00 \\
\hline attend conference & $54(37.5)$ & $43(44.8)$ & 0.32 \\
\hline operation demonstration & $64(44.4)$ & $42(43.8)$ & 0.40 \\
\hline Obstacles in training & & $48(50)$ & 0.48 \\
\hline I am not allowed by hospital & $41(28.5)$ & & 0.24 \\
\hline nobody replaces me at work & $80(55.6)$ & $20(20.8)$ & 0.44 \\
\hline I am not allowed due to family reasons & $25(17.4)$ & $59(61.5)$ & 0.12 \\
\hline I cannot afford the training & $53(36.8)$ & $9(9.4)$ & 0.06 \\
\hline I cannot learn the skills I wanted & $46(31.9)$ & $29(30.2)$ & $43(44.8)$ \\
\hline Values are presented as number (\%). & & & \\
\hline
\end{tabular}

Table 4 summarized their interest in major surgical procedures and self-assessed knowledge gap. For surgeons in private hospitals, $69.2 \%$ of them intended to learn rhinoplasty, and eye plastic surgery. Fat transplant was their third interesting procedures, which coincided with their self-assessed knowledge gap. For surgeons working in public hospitals, their top three interesting surgical procedures were eye plastic surgery, rhinoplasty, and minimally invasive plastic surgery, in terms of knowledge gap, they believed that they had more knowledge gap in external genitalia, perineal surgery, rather than eye plastic surgery. 
Table 4

Summary of major surgical procedures intended to study and self-assessed knowledge gap by aesthetic plastic surgeons

\begin{tabular}{|c|c|c|c|}
\hline & $\begin{array}{l}\text { Public } \\
\text { hospital ( }= \\
\text { 144) }\end{array}$ & $\begin{array}{l}\text { Private } \\
\text { hospital ( }= \\
96)\end{array}$ & $\begin{array}{l}P \\
\text { value }\end{array}$ \\
\hline \multicolumn{4}{|l|}{ Major surgical procedures } \\
\hline rhinoplasty & $49(58.3)$ & $45(69.2)$ & 0.232 \\
\hline eye plastic surgery & $62(73.8)$ & $42(64.6)$ & 0.302 \\
\hline fat transplant plastic surgery & $34(40.5)$ & $32(49.2)$ & 0.368 \\
\hline breast plastic surgery & $15(17.9)$ & $19(29.2)$ & 0.149 \\
\hline minimally invasive plastic surgery & $39(46.4)$ & $16(24.6)$ & 0.010 \\
\hline thread lifting & $18(21.4)$ & $13(20)$ & 0.992 \\
\hline \multicolumn{4}{|l|}{ Knowledge gap*, median (IQR) } \\
\hline gap in eye plastic surgery & $1(0,2)$ & $2(1,2)$ & 0.866 \\
\hline rhinoplasty & $2(1,3)$ & $2(0,2)$ & 0.770 \\
\hline ear plastic surgery & $1(0,2)$ & $1(1,2)$ & 0.897 \\
\hline facial wrinkles and contours & $1(1,2)$ & $1(1,2)$ & 0.648 \\
\hline lip plastic surgery & $1(0,2)$ & $1(1,2)$ & 0.288 \\
\hline hair transplant & $1(0,2)$ & $1(0,2)$ & 0.484 \\
\hline breast plastic surgery & $1(0,2)$ & $1(1,2)$ & 0.941 \\
\hline bariatric surgery and body shaping & $1(0,2)$ & $1(1,2)$ & 0.742 \\
\hline external genitalia, perineal surgery & $2(0,2)$ & $1(0,2)$ & 0.355 \\
\hline $\begin{array}{l}\text { new technologies such as fat transplant, endoscope, and } \\
\text { other minimally invasive plastic surgery }\end{array}$ & $2(0,2)$ & $2(0,2)$ & 0.593 \\
\hline
\end{tabular}

\subsection{Qualitative analysis on the current continuing professional education system for aesthetic plastic surgeons}

Continuing medical education programs are under the management and organization of medical associations at municipal or provincial levels. Doctors in public hospitals are required to abstain a minimum credit by attending different continuing education programs. However, the doctors in private 
hospitals are not compulsory required to get the credits. In-depth interview revealed that most continuing professional education conferences were co-organized by public and private hospitals. As non-profit medical organizations, the department of aesthetic plastic surgery in most public hospitals were merged with burn surgery, therefore, they focused more on their social responsibility in repair and reconstructive surgery. Meanwhile, as a base to train medical students, public hospitals paid more attention on academic development and researches on basic and clinical technologies. By contrast, private aesthetic plastic hospitals were for-profit originations and laid more emphasis on improving customers' experience. Since aesthetic plastic procedure were not covered by insurance schemes, customers were more likely to visit private hospitals for operations because of more comfortable environment and individualized services. These organizational differences between public hospitals and private hospitals led to different requirements of aesthetic plastic surgeons in their respective institutions, reflecting their needs difference in continuing professional education.

\section{Discussion}

This study suggested that after decades of rapid development of Chinese plastic surgery, the demographic data in private hospitals were quite similar to that of the public hospitals in such an economic developed province. In general, the plastic surgeons were massively young, with comparatively short working years. In addition, almost two thirds of them transferred from other specialties. The only difference was almost half of the doctors in public hospitals had a graduate degree, whereas, a quarter of them had a graduate degree in private hospitals. From the demographic data we concluded that it would be imperative to reinforce continuing professional education for aesthetic plastic surgery, meanwhile, considering the difference in demographic status.

In this study, the fact that half of the surgeons attended continuing professional education less than three times in a year with limited affordable expense had great significance on planners in designing programs. Although most surgeons preferred to further their studies in a tertiary hospital, the chances were very limited $[13,14]$. This study suggested that short course focused on specific topic with operation procedures demonstrations by experts should be a favorable training method, similar to other researches in surgical education[15]. Meanwhile, more attention should be laid on skills improvement in designing training curriculum, and with more consideration of reasonable price and flexible time for attendees.

This study also revealed a fact that rhinoplasty and new technologies such as fat transplant, minimally invasive plastic surgery were great concerning procedures for surgeons either in public hospitals or in private hospitals. The results of self-assessed knowledge gap showed surgeons in public hospitals intend to have more continuing professional education in genitoperineal surgery, a newly popular surgical procedure in recent years [16]; while the surgeons in private hospitals believed more improvement should be made on eyes plastic surgery since blepharoplasty is the most popular procedure in China[17]. The difference in training objectives was due to the different customer groups and social roles for public and private hospitals. In specific, the public hospitals also took social responsibility in repair and 
reconstructive surgery, while, the private hospitals were more market-oriented, mainly focused aesthetic surgery.

This study tested the hypothesis that the demographic difference for aesthetic plastic surgeons between public and private hospitals were getting narrow. However, the organizational difference had influence on their respective training needs, which coincided with Goldstein training mode.

\section{Conclusion}

The demographic disparity of aesthetic plastic surgeons between public hospitals and private hospitals was small. Continuing professional education was very important to improve the level of massive young aesthetic plastic surgeons. To design the training curriculum focused on practical skills, especially a short training course elicited by expert in rhinoplasty, eye surgery, and new technologies such as fat transplant, minimal invasive plastic surgery would be favorable. Meanwhile, the demographic status of aesthetic plastic surgeons and organizational needs should be taken into consideration.

\section{Declarations}

\section{Ethics approval and consent to participate}

The protocol was approved by the Ethics Committee of Southern Medical University, China. Informed Consent Informed consent was obtained from all participants. All procedures performed in studies involving human participants were in accordance with the ethical standards of the institutional and/or national research committee and with the 1964 Helsinki declaration and its later amendments or comparable ethical standards.

\section{Consent for publication}

All authors are consent for the publication of this manuscript.

\section{Competing interests}

The authors declare that they have no conflicts of interest.

\section{Funding}

Financial support was obtained under the support of China Postdoctoral Science Foundation Grant (2019M652967) and the National Natural Science Foundation of China (Grant No.81772104, No.81701929, No.81971889, No.81902013).

\section{Authors' contributions}

QJ and YYH contributed equally in literature review, study design, data collection, analysis, interpretation of results, and manuscript drafting. HZQ and MY proposed the research idea and helped organize the 
whole research process. $\mathrm{JJ}$ attended the data collection, data analysis and interpretation of results., as a native English speaker, he also checked and proofread the manuscript. The corresponding author attests that all listed authors meet the authorship criteria.

\section{Acknowledgements}

This study is a part of the first author's thesis in partial fulfillment of the requirements for a doctoral degree in the department of plastic and aesthetic surgery, Nanfang hospital at Southern Medical University China.

\section{Availability of data and materials}

The datasets used and analyzed during the current study are available from the corresponding author on reasonable request.

\section{References}

1. Pan S, Yin $\mathrm{K}$, Zhang Y, Xu H, Wei M: The transforming training pathway of plastic and craniofacial surgery in China. The Journal of craniofacial surgery 2015, 26(2):347-349.

2. Zheng J, Zhang B, Yin Y, Fang T, Wei N, Lineaweaver WC, Zhang F: Comparison of Plastic Surgery Residency Training in United States and China. Ann Plast Surg 2015, 75(6):672-678.

3. Wei L: Selling Cosmetic Surgery and Beauty Ideals: The Female Body in the Web Sites of Chinese Hospitals. Womens Studies in Communication 2012, 35(1):68-95.

4. Li GS, Dong M-M, Liu L-B, Hu X-Y: Ethical Issues in Chinese Aesthetic Surgery. Aesthetic plastic surgery, 38(5):994-1000.

5. Zheng J, Zhang B, Yin Y, Fang T, Wei N, Lineaweaver WC, Zhang F: Comparison of Plastic Surgery Residency Training in United States and China. Ann Plast Surg 2015, 75(6):672-678.

6. Jin R, Luo X, Wang X, Ma J, Liu F, Yang Q, Yang J, Wang X: Complications and Treatment Strategy After Breast Augmentation by Polyacrylamide Hydrogel Injection: Summary of 10-Year Clinical Experience. Aesthetic plastic surgery 2018, 42(2):402-409.

7. Song K, Scott A, Sivey P, Meng Q: Improving Chinese primary care providers' recruitment and retention: a discrete choice experiment. Health policy and planning 2015, 30(1):68-77.

8. Schneider LF, Barr J, Saadeh PB: A nationwide curriculum analysis of integrated plastic surgery training: is training standardized? Plast Reconstr Surg 2013, 132(6):1054e-1062e.

9. Gaspard J, Yang CM: Training needs assessment of health care professionals in a developing country: the example of Saint Lucia. BMC medical education 2016, 16:112.

10. Yi Y, Chongsuvivatwong V, Sriplung H, Hu G, McNeil E, Feng Q, Zhou H, Wei B: Unmet need in continuing medical education programs for rural Chinese township health professionals. J Educ Eval Health Prof 2015, 12:25. 
11. David JA, Rifkin WJ, Saadeh PB, Sinno S: Assessing the Value of a Multimedia-Based Aesthetic Curriculum in Plastic Surgery Residency: A Single-Center Pilot Study. Aesthet Surg J 2018, 38(12):NP216-NP224.

12. Xiaowen F: An Evolution Analysis of Regional Economic Development Disparities in Guangdong Based on the FPCA. In: Studies on China's Special Economic Zones 3. edn.: Springer; 2020: 103-113.

13. Hu G, Yi Y: Is a decentralized continuing medical education program feasible for Chinese rural health professionals? J Educ Eval Health Prof 2016, 13:18-18.

14. Mo Y, Hu G, Yi Y, Ying Y, Huang H, Huang Z, Lin J: Unmet needs in health training among nurses in rural Chinese township health centers: a cross-sectional hospital-based study. J Educ Eval Health Prof 2017, 14:22-22.

15. Brunckhorst $O$, Challacombe B, Abboudi H, Khan M, Dasgupta P, Ahmed K: Systematic review of live surgical demonstrations and their effectiveness on training. British Journal of Surgery 2014, 101(13):1637-1643.

16. Goodman MP: Female cosmetic genital surgery. Obstetrics \& gynecology 2009, 113(1):154-159.

17. Hwang HS, Spiegel JH: The effect of "single" vs "double" eyelids on the perceived attractiveness of Chinese women. Aesthetic surgery journal 2014, 34(3):374-382. 